\title{
Technical Approach and Results from the Fuels Pathway on an Alternative Selection Case Study
}

R. Youngblood

C. Smith

September 2013
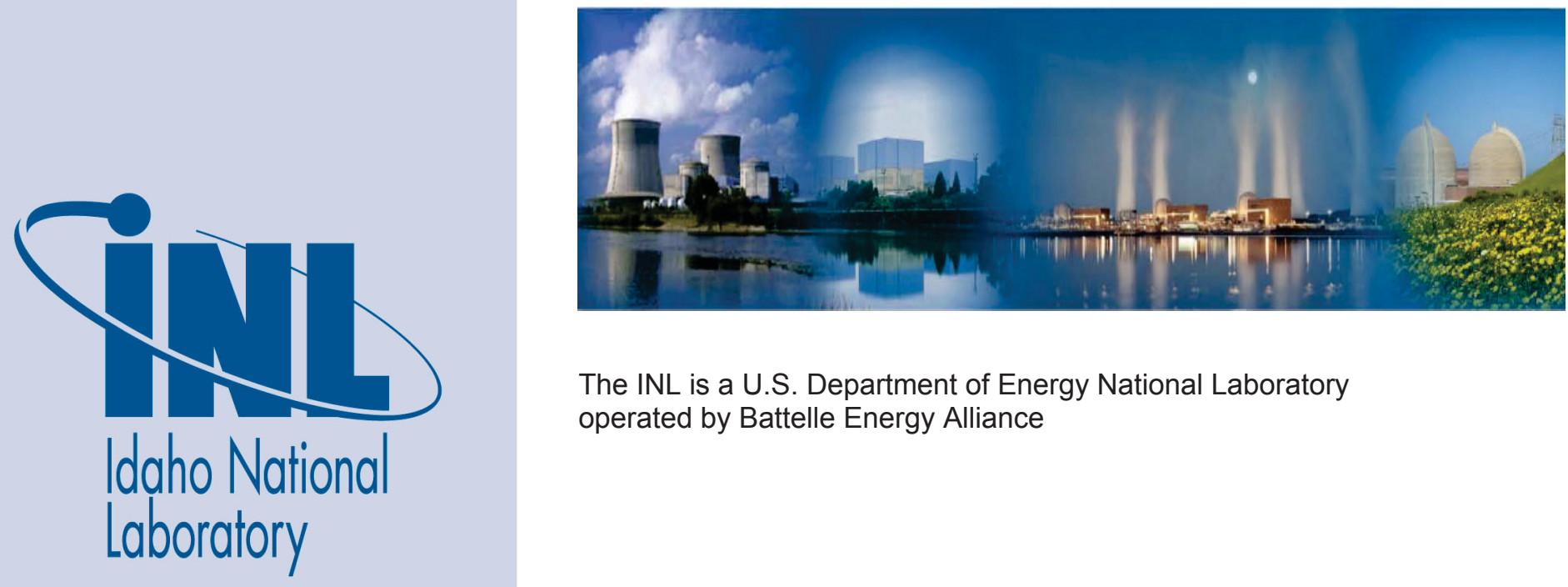

The INL is a U.S. Department of Energy National Laboratory operated by Battelle Energy Alliance 


\section{DISCLAIMER}

This information was prepared as an account of work sponsored by an agency of the U.S. Government. Neither the U.S. Government nor any agency thereof, nor any of their employees, makes any warranty, expressed or implied, or assumes any legal liability or responsibility for the accuracy, completeness, or usefulness, of any information, apparatus, product, or process disclosed, or represents that its use would not infringe privately owned rights. References herein to any specific commercial product, process, or service by trade name, trade mark, manufacturer, or otherwise, does not necessarily constitute or imply its endorsement, recommendation, or favoring by the U.S. Government or any agency thereof. The views and opinions of authors expressed herein do not necessarily state or reflect those of the U.S. Government or any agency thereof. 
INL/EXT-13-30195

Revision 0

\title{
Technical Approach and Results from the Fuels Pathway on an Alternative Selection Case Study
}

\author{
R. Youngblood \\ C. Smith
}

September 2013

Idaho National Laboratory Idaho Falls, Idaho 83415

http://www.inl.gov

Prepared for the

U.S. Department of Energy

Office of Nuclear Energy

Under DOE Idaho Operations Office

Contract DE-AC07-05ID14517 



\section{EXECUTIVE SUMMARY}

Safety is central to the design, licensing, operation, and economics of Nuclear Power Plants (NPPs). Consequently, the ability to better characterize and quantify safety margin holds the key to improved decision making about light water reactor design, operation, and plant life extension. A systematic approach to characterization of safety margins and the subsequent margins management options represents a vital input to the licensee and regulatory analysis and decision making that will be involved.

The purpose of the Risk Informed Safety Margin Characterization (RISMC) Pathway research and development (R\&D) is to support plant decisions for risk-informed margins management by improving economics and reliability, and sustaining safety, of current NPPs. Goals of the RISMC Pathway are twofold: (1) Develop and demonstrate a risk-assessment method coupled to safety margin quantification that can be used by NPP decision makers as part of their margin recovery strategies. (2) Create an advanced "RISMC toolkit" that enables more accurate representation of NPP safety margin.

In order to carry out the R\&D needed for the Pathway, the Idaho National Laboratory is performing a series of case studies that will explore methods- and tools-development issues, in addition to being of current interest in their own right. One such study is a comparative analysis of safety margins of plants using different fuel cladding types: specifically, a comparison between current-technology Zircaloy cladding and a notional "accident-tolerant" (e.g., SiC-based) cladding. The present report discusses the formulation of the analysis needed to support an intelligible comparison of margins in plants using the two cladding types, and what sorts of capabilities will be needed.

The approach and lessons learned from this case study will be included in future Technical Basis Guides produced by the RISMC Pathway. These guides will be the mechanism for developing the specifications for RISMC tools and for defining how plant decision makers should propose and evaluate margin recovery strategies.

This report discusses the following points.

- There is no particular reason to believe that regulatory acceptance criteria (e.g., peak clad temperature $<2200 \mathrm{~F}$ ) will be the same for new cladding types as for the traditional cladding type; comparison of cladding behavior for licensing purposes needs to be carried out in light of the higher-level purposes of the acceptance criteria. The technical basis for the recently-proposed change to the ECCS rule explicitly says as much.

- It is clear a priori that a meaningful analysis must analyze plant-level behavior for each cladding type, as opposed to simply looking at the physical properties of cladding.

- In order to compare plant-level behavior keeping all but cladding the "same," it is necessary to exercise considerable care in formulating inputs to the simulation of time histories. The technique needed for this is discussed.

- Recent simulation work carried out for another program, while confirming the idea that "accident-tolerant" cladding does behave better in some respects than today's cladding, provides specific examples showing why plant-level analysis is needed in order to justify the comparison.

A detailed case study process that has been formulated in light of the above is provided. 


\section{CONTENTS}

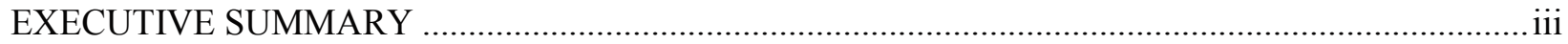

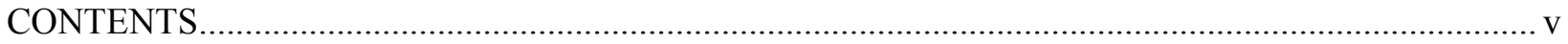

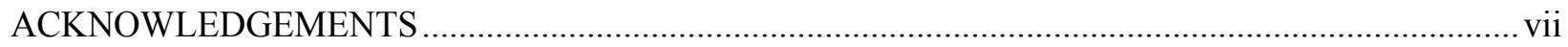

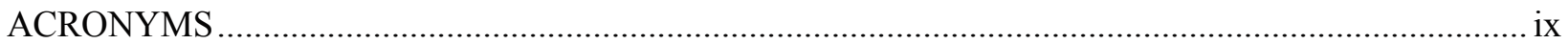



2. BACKGROUND ON PREVIOUS ANALYSIS OF CLADDING …...................................... 3

2.1 Basis for Original Regulatory Acceptance Criteria.............................................................. 3

2.2 Recently-Proposed Rulemaking on Regulatory Acceptance Criteria .................................. 3

2.3 Preliminary Modeling of Behavior of Candidate Accident-Tolerant Fuel in Severe



2.4 Preliminary Comparison of Zircaloy-clad Fuel with Hypothetical “Accident-

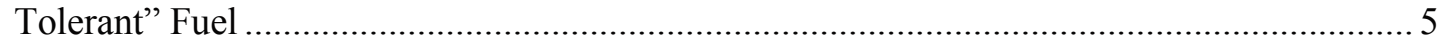

3. FORMULATING A CASE STUDY TO DEVELOP A MARGINS-BASED COMPARISON OF CLADDING BEHAVIOR ….................................................................. 7



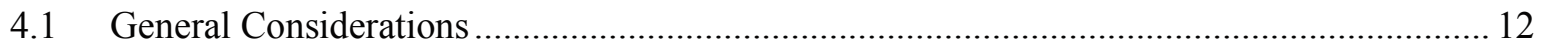

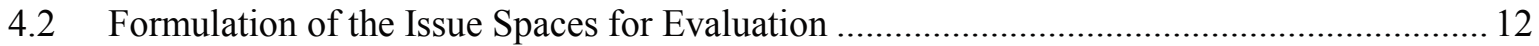

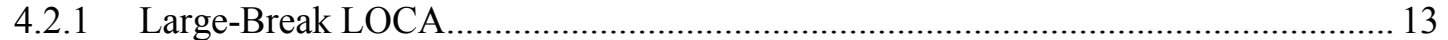

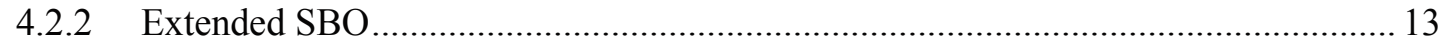

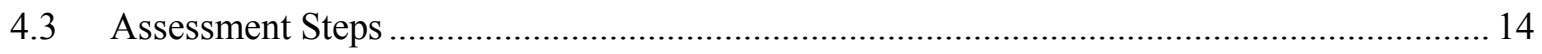



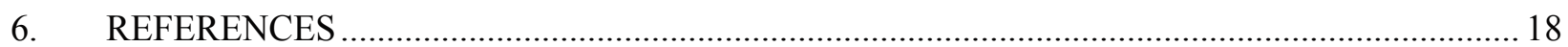




\section{ACKNOWLEDGEMENTS}

In addition to having been informed by several years of work in the Risk-Informed Safety Margin Characterization Pathway within the Light Water Reactor Sustainability Program, this report has benefited from several discussions with Shannon Bragg-Sitton on the subject of her work for the Advanced Fuels Campaign. 


\section{ACRONYMS}

$\begin{array}{ll}\text { ATF } & \text { Accident-Tolerant Fuel } \\ \text { DOE } & \text { Department of Energy } \\ \text { DB } & \text { Design Basis } \\ \text { ECCS } & \text { Emergency Core Cooling System } \\ \text { FMEA } & \text { Failure Modes \& Effects Analysis } \\ \text { INL } & \text { Idaho National Laboratory } \\ \text { LWR } & \text { light water reactor } \\ \text { LWRS } & \text { light water reactor sustainability } \\ \text { NPP } & \text { nuclear power plant } \\ \text { NRC } & \text { Nuclear Regulatory Commission } \\ \text { PIRT } & \text { Phenomena Identification \& Ranking Table } \\ \text { PRA } & \text { probabilistic risk assessment } \\ \text { R\&D } & \text { research and development } \\ \text { RISMC } & \text { Risk Informed Safety Margin Characterization } \\ \text { Si } & \text { Silicon Carbide } \\ \text { SSC } & \text { system, structure, and component } \\ \text { T-H } & \text { thermal-hydraulics }\end{array}$




\section{RISMC PATHWAY BACKGROUND}

Safety is central to the design, licensing, operation, and economics of nuclear power plants (NPPs). As the current light water reactor (LWR) NPPs age beyond 60 years, there are possibilities for increased frequency of systems, structures, and components (SSC) degradations or failures that initiate safetysignificant events, reduce existing accident mitigation capabilities, or create new failure modes. Plant designers commonly "over-design" portions of NPPs and provide robustness in the form of redundant and diverse engineered safety features to ensure that, even in the case of well-beyond design basis scenarios, public health and safety will be protected with a very high degree of assurance. This form of defense-indepth is a reasoned response to uncertainties and is often referred to generically as "safety margin."

The ability to better characterize and quantify safety margin holds the key to improved decision making about LWR design, operation, and plant life extension. A systematic approach to characterization of safety margin and the subsequent margin management options represents a vital input to the licensee and regulatory analysis and decision making that will be involved. In addition, as research and development (R\&D) in the LWR Sustainability (LWRS) Program and other collaborative efforts yield new data, sensors, and improved scientific understanding of physical processes that govern the aging and degradation of plant SSCs (and concurrently support technological advances in nuclear reactor fuels and plant instrumentation and control systems) needs and opportunities to better optimize plant safety and performance will become known. This interaction of degradation understanding and potential impacts to plant margins is shown in Figure 1. To support decision making related to economics, readability, and safety, the RISMC Pathway [1] provides methods and tools that enable mitigation options known as margins management strategies.

The purpose of the RISMC Pathway R\&D is to support plant decisions for risk-informed margin management with the aim to improve economics, reliability, and sustain safety of current NPPs. As the lead Department of Energy (DOE) Laboratory for this Pathway, the Idaho National Laboratory (INL) is tasked with developing and deploying methods and tools that support the quantification and management of safety margin and uncertainty.

Goals of the RISMC Pathway are twofold:

1. Develop and demonstrate a risk-assessment method coupled to safety margin quantification that can be used by NPP decision makers as part of their margin recovery strategies.

2. Create an advanced "RISMC toolkit" that enables more accurate representation of NPP safety margin. 


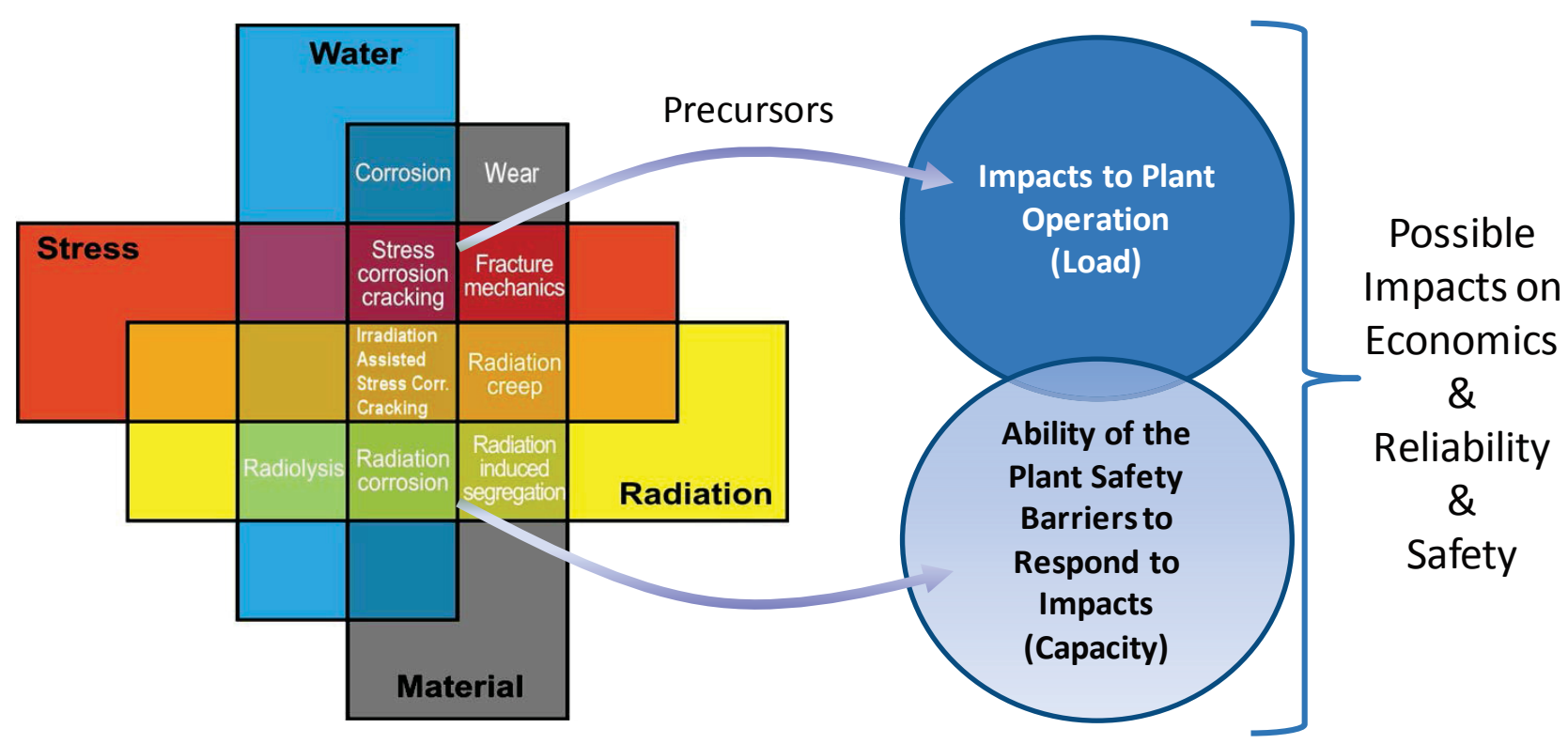

Figure 1 Representation of the interaction of degradation mechanisms that may impact plant operations and safety barriers if left unmitigated.

One of the primary goals of the Pathway is to develop the capability to propose and evaluate margin recovery strategies (i.e., proposed changes to SSCs or plant procedures that work to mitigate margin degradation due to aging or plant modifications, including margin enhancement in some areas to compensate for degradation in others). If a plant safety margin is degraded, the RISMC methods and tools will serve to model, measure, and maintain compensating margins in other active and passive SSCs for normal and off-normal conditions. Moving beyond current limitations in safety analysis, the Pathway will develop techniques to conduct analysis using simulation-based studies of safety margins where "margin" go beyond the typical engineering margins concept. For example, licensing margins as a part of the plant's design basis are not the only ones protecting the public; plant safety also depends on margins that are not necessarily analyzed in licensing.

The INL approach to the research and development needed for the RISMC Pathway is based on a series of case studies that serve to focus development of tools and methodology, in addition to being of interest in their own right. One such case study is a margins-based comparison of the behavior of Zircaloy cladding with new cladding designs based on silicon carbide (SiC). Zircaloy cladding works well under normal conditions, but it is well known that loss of core cooling can lead to core melt, with release of radioactive material into containment, as occurred at Three Mile Island in 1979 [2], and release of radioactive material from containment, as occurred at Fukushima in 2011[3]. In addition to loss of the fuel cladding barrier in these accidents, a significant amount of combustible hydrogen was also produced, leading to additional damage and affecting the release of radioactive material at Fukushima. The behavior of $\mathrm{SiC}$ at corresponding temperatures seems to be more robust than the behavior of Zircaloy, suggesting that cladding using $\mathrm{SiC}$ might have significantly enhanced margin to failure in loss-of-cooling scenarios. However, the comparison must consider multiple attributes in multiple scenario types. The present report discusses the analysis needed to support such a study. 


\section{BACKGROUND ON PREVIOUS ANALYSIS OF CLADDING 2.1 Basis for Original Regulatory Acceptance Criteria}

A useful summary of the original technical basis for current regulatory acceptance criteria for accident analysis emergency core cooling system (ECCS) performance of LWRs is contained in [4]. That reference reconstructs the reasoning behind the current acceptance criteria $\{<17 \%$ oxidation AND $<2200$ F peak clad temperature $\}$. The Commission (at that time, the Atomic Energy Commission) considered it important to maintain coolable geometry of the core, both during an accident and for a long time thereafter. Among other things, this meant that the fuel should not shatter, either as a result of stresses imposed during the accident or stresses imposed during subsequent fuel handling. This meant that the fuel structure (specifically including the cladding) should remain ductile. Satisfaction of the oxidation and peak temperature criteria is meant to assure maintenance of ductility, whereas violation of either criterion creates a potential for loss of ductility. It is additionally explained in [4] that in order for the desired conclusion regarding ductility to be supportable, the analysis needs to apply the Baker-Just correlation.

These acceptance criteria are very different from the criteria applied in risk analysis, as will be illustrated in Section 2.3. Probabilistic risk analysis for nuclear power plants is usually implicitly about exposure of the public to releases of radioactive material in the course of core melt accidents, and for that purpose, different (more lenient) failure criteria are applicable. However, the current regulatory acceptance criteria are not "conservative" relative to the regulatory concern being addressed. (In fact, as discussed in the next subsection, they are non-conservative for high-burnup fuel.) Maintaining fuel integrity during and after accidents arguably needs to be considered in the margins-informed comparison of cladding merits.

\subsection{Recently-Proposed Rulemaking on Regulatory Acceptance Criteria}

Recently, work sponsored by the Nuclear Regulatory Commission (NRC) suggested that the current regulatory acceptance criteria are actually non-conservative for higher-burnup fuel: that there exist embrittlement mechanisms not contemplated in the original criteria, and that the $17 \%$ limit on oxidation is not adequate to preserve the level of ductility that the Commission originally deemed to be warranted for adequate protection. At this writing, a rulemaking is being contemplated to address several points, including this one. Excerpts from a relevant Commission paper [5] are provided below.

Information developed through the NRC's high burnup fuel research program has identified that the current criterion for preventing fuel cladding embrittlement may not be adequate to ensure the health and safety of the public. As discussed in Sections II and V of this Statement of Considerations, zirconium-based alloy fuel cladding materials may be subject to embrittlement at a lower combination of temperature and level of oxygen absorption (17 percent) than currently allowed under $\S 50.46(b)(1)$ due to absorption of hydrogen during normal operation. The proposed rule would correct those limits initially established to prevent embrittlement of zirconium-based alloy cladding material based on the new research information. In addition, the research work has identified new phenomena, such as breakaway oxidation and oxygen diffusion from the cladding inside surfaces, which are believed to further adversely affect the fuel cladding embrittlement process. Thus, post quench ductility (which is necessary to ensure coolable core geometry) ${ }^{3}$ is not guaranteed following a postulated LOCA. The proposed rule would establish new requirements for zirconium-based alloys to prevent breakaway oxidation and account for oxygen diffusion from the oxide fuel pellet during the operating life of the fuel. In sum, the NRC believes that imposing the requirements of the proposed rule is necessary to prevent embrittlement of fuel cladding and to restore the rule to the level of reasonable assurance of adequate protection to public health and safety.

${ }^{3}$ The Commission concluded, as part of the 1973 Emergency Core Cooling System rulemaking, that retention of ductility in the zircaloy cladding material was determined to be the best guarantee of its remaining intact during the hypothetical loss-of-coolant accident, thereby maintaining a coolable 
core geometry. See Acceptance Criteria for Emergency Core Cooling Systems for Light-Water-

Cooled Nuclear Power Reactors, CLI-73-39, at page 1098 (December 28, 1973).

With respect to current nuclear power plant licensees, the NRC assumes that imposition of the proposed rule would constitute backfitting as defined in $\$$ 50.109(a)(1). However, the NRC believes that the proposed rule must be imposed upon current nuclear power plant licensees in order to ensure adequate protection to the public health and safety by restoring that level of protection (i.e., reasonable assurance of adequate protection) which the NRC thought would be achieved (throughout the entire term of licensed operation) by the current rule. Therefore, the NRC has determined that the proposed rule is necessary to ensure that the facility provides adequate protection to the health and safety of the public, and that a backfit analysis as described in $\S \S 50.109(\mathrm{a})(3)$ and (b) need not be prepared under the exception in $\S 50.109(\mathrm{a})(4)(\mathrm{ii})$.

For present purposes, the key points are the following.

- Cladding performance cannot be evaluated in isolation. Cladding performance and ECCS performance need to be considered together.

- Models for cladding performance even within the design basis will need to be updated for regulatory purposes and for purposes of this case study.

- Effort needs to be expended in searching the regulatory issue space for the limiting case. This has always been clear, but now it is explicit, and there may be more stringent reporting requirements on the analysis ("ECCS performance must be demonstrated for a range of postulated loss-ofcoolant accidents of different sizes, locations, and other properties, sufficient to provide assurance that the most severe postulated loss-of-coolant accidents have been identified. ECCS performance must be demonstrated for the accident, and the post-accident recovery and recirculation period." SECY-12-0034)

\subsection{Preliminary Modeling of Behavior of Candidate Accident- Tolerant Fuel in Severe Accidents}

Severe accidents have been modeled extensively since TMI. In NRC guidance, an accident is "severe" if it is more severe than an event within the design basis. [6] For operating LWRs using today's cladding, an accident is arguably "severe" if a significant amount of hydrogen is evolved, whether or not the core itself completely loses geometry, because that amount of hydrogen is beyond the design basis.

A recent paper by Merrill and Bragg-Sitton (reference [7]) compares the behavior of Zircaloy with a notional version of $\mathrm{SiC}$ cladding in a "TMI event." The comparison is based on MELCOR simulations, and used MELCOR failure criteria for fuel, which are based on loss of geometry during the accident, and do not consider the regulatory acceptance criterion discussed above. The assumed event progression matches what happened at TMI from an active component point of view: in the simulation, pumps start and stop at the exact same time they started and stopped in the actual event, valves open and close in the simulation as they did in the event, and so on.

The figures below (Figures 2 and 3) are taken from [7], which presented two simulations of the "TMI event," one with Zircaloy and one with SiC. Figure 2 shows that the temperature behavior of the Zircaloy run is very different from the temperature behavior of the $\mathrm{SiC}$ run. But since decay heat and the timing and rates of injection are the same in the two cases, the temperature difference is due largely to differences in the cladding-water reaction. Those reactions are the focus of Figure 3 of reference [7]. Note that the vertical axis is a log scale. It is seen that sometimes the $\mathrm{Zr}$-water reaction contributes significantly more heat than decay heat contributes, and much more than the oxidation heating associated with SiC contributes. 


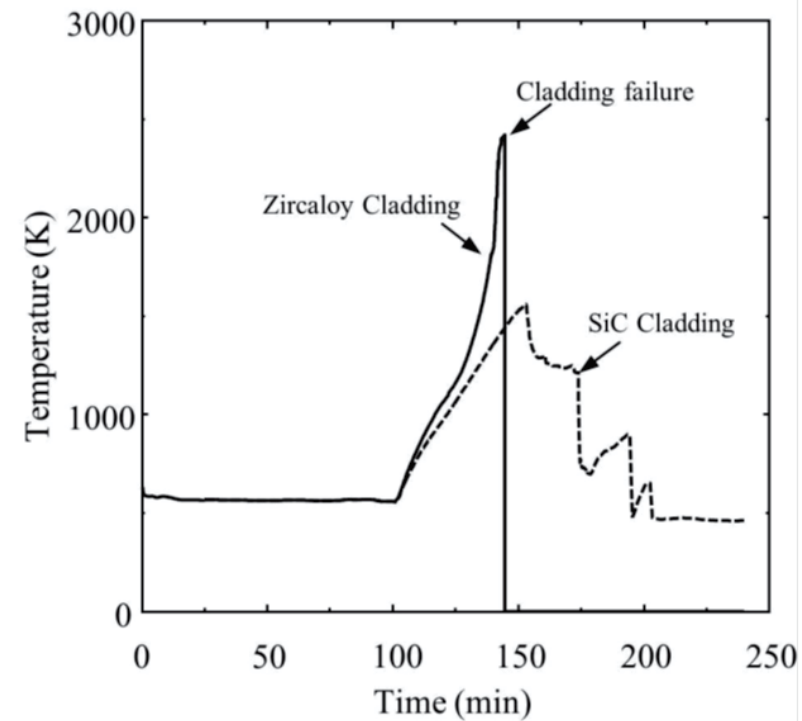

Figure 2 Comparison of MELCOR predicted maximum cladding temperature during a TMI-2 accident. [7]



Figure 3 Comparison of MELCOR predicted clad oxidation heating produced during a TMI-2 accident. [7]

Pros and cons of this comparison are discussed in a later subsection. The comparison is suggestive, and carries the point that a $\mathrm{SiC}$ model has been implemented in MELCOR, but was not carried out in a way that would comprehensively support a technology downselect.

\subsection{Preliminary Comparison of Zircaloy-clad Fuel with Hypothetical “Accident-Tolerant" Fuel}

Note: This subsection paraphrases selected points made in a review draft of [8] prepared by BraggSitton et al., which compares simulations of plant behavior in selected severe-accident scenarios assuming today's fuel cladding with simulations assuming notional "accident-tolerant" fuel (ATF) cladding.

It is inappropriate to furnish details of those predecisional discussions in the present report. However, simulations performed for that report furnish instances of certain general points made here, and moreover have driven certain details in the formulation of the detailed case study steps enumerated in a later section of the present report, which beneficial influence is hereby acknowledged.

Selected key points from [8]:

- In the simulations involving ATF, very high temperatures are reached in some areas for some scenarios, in contrast to results for today's conventional fuel cladding. This occurs because in certain of the scenarios modeled, and given the modeling assumptions, today's fuel fails structurally and relocates to the lower portion of the vessel, while the ATF cases are modeled as retaining geometry. This raises two categories of issues:

- Since some portions of the overall system experience harsher environments in the ATF case than in the conventional-cladding case, the comparison needs to treat carefully the question of which plant-level outcome is "better." In fact, which case is "better" might even depend on the duration of the loss of cooling. 
- The observation of very high temperatures in the ATF case reinforces the need to determine carefully which failure modes of what internal components are limiting in the ATF case that were NOT limiting with today's fuel cladding in the system.

The simulations done for [8] point to these issues, but the FMEA/PIRT exercises implied by them were beyond the scope of that effort. These steps are, however, called out in the process described later in Section 4. 


\section{FORMULATING A CASE STUDY TO DEVELOP A MARGINS- BASED COMPARISON OF CLADDING BEHAVIOR}

Numerous previous discussions of the RISMC load-capacity approach ${ }^{\mathrm{a}}$ have had a notional character, in that they supposed that in the case of cladding, the "load" is the temperature and the "capacity" is the ability of the cladding to withstand the load (i.e., increased temperatures due to accident scenarios). But it has been realized for some time that in some cases, this picture will be too simple. For example, the following note appeared in a summary [10] of the RISMC Working Group meeting held in January of 2010:

“Capacity" of Zr-Clad Fuel:

There is at least some agreement within the group that studies should be undertaken that "do the logo." That is, for specific cases of legitimate interest, work should be done to compute probabilistic load spectra and probabilistic capacity spectra. Since fuel and cladding capacity (ability to withstand harsh physical environments, e.g., high temperature) will be of interest for several reasons, the suggestion was made that a good case study this year would be to formulate and quantify a fuel capacity construct for Zr-clad fuel. This would entail unearthing the technical basis (experimental and analytical) for the existing regulatory acceptance criteria, unearthing any additional evidence pertinent to fuel capacity, determining how to characterize capacity really, and then applying the evidence as best we can to construct the "curve" (probably a more complicated construct than a single curve). Although we frequently use the peak cladding temperature as an example in casual discussion, because its spectrum can easily be displayed notionally on a graph whose horizontal axis is "temperature," it is recognized that actual fuel failure probability is a more complex function of operating history and transient evolution than that. So "doing the logo" for fuel capacity is not trivial; it may involve several coupled variables. The benefits, however, are expected to be more than purely conceptual, if SiC-clad fuel reaches a stage of development at which a careful comparison of cladding capacities would inform an important decision regarding deployment of $\mathrm{SiC}$ cladding.

As anticipated in the above excerpt, and as illustrated in [7,8], the structural-mechanics load-capacity metaphor is oversimplified for the cladding discussion, for example:

- In structural mechanics discussions, the "load" is a force (e.g., a weight) externally imposed on a structure, and the "capacity" is that structure's ability to survive the load without structural failure.

- In the fuel discussion, the temperature reading at a given instant is not "externally" imposed, but more properly viewed as the combination of decay heat plus something the cladding is doing to itself, namely, undergoing an exothermic chemical reaction whose heat release, some of the time at least, actually exceeds that of decay heat.

In some scenarios, $\mathrm{SiC}$ reacts much less than Zircaloy, and (at least in the "TMI" event) experiences lower temperature as a result. The point is not just that $\mathrm{SiC}$ would tolerate elevated temperatures better; the point is also that exposed to the same decay heat and steam environment, $\mathrm{SiC}$ will not reach the same elevated temperature as Zircaloy, at least in the "TMI event" analyzed in [7] (see Figure 4).

\footnotetext{
a The load-capacity refers to a picture of load pdf overlapping capacity pdf, called "the logo" years ago (e.g., in [9]) as a shorthand way of referring to the key underlying difference between "margin" as understood within the RISMC project (i.e., probabilistically) and "margin" as seen by the broader community of practice (a distance between a nominal performance metric value and a designated threshold value).
} 


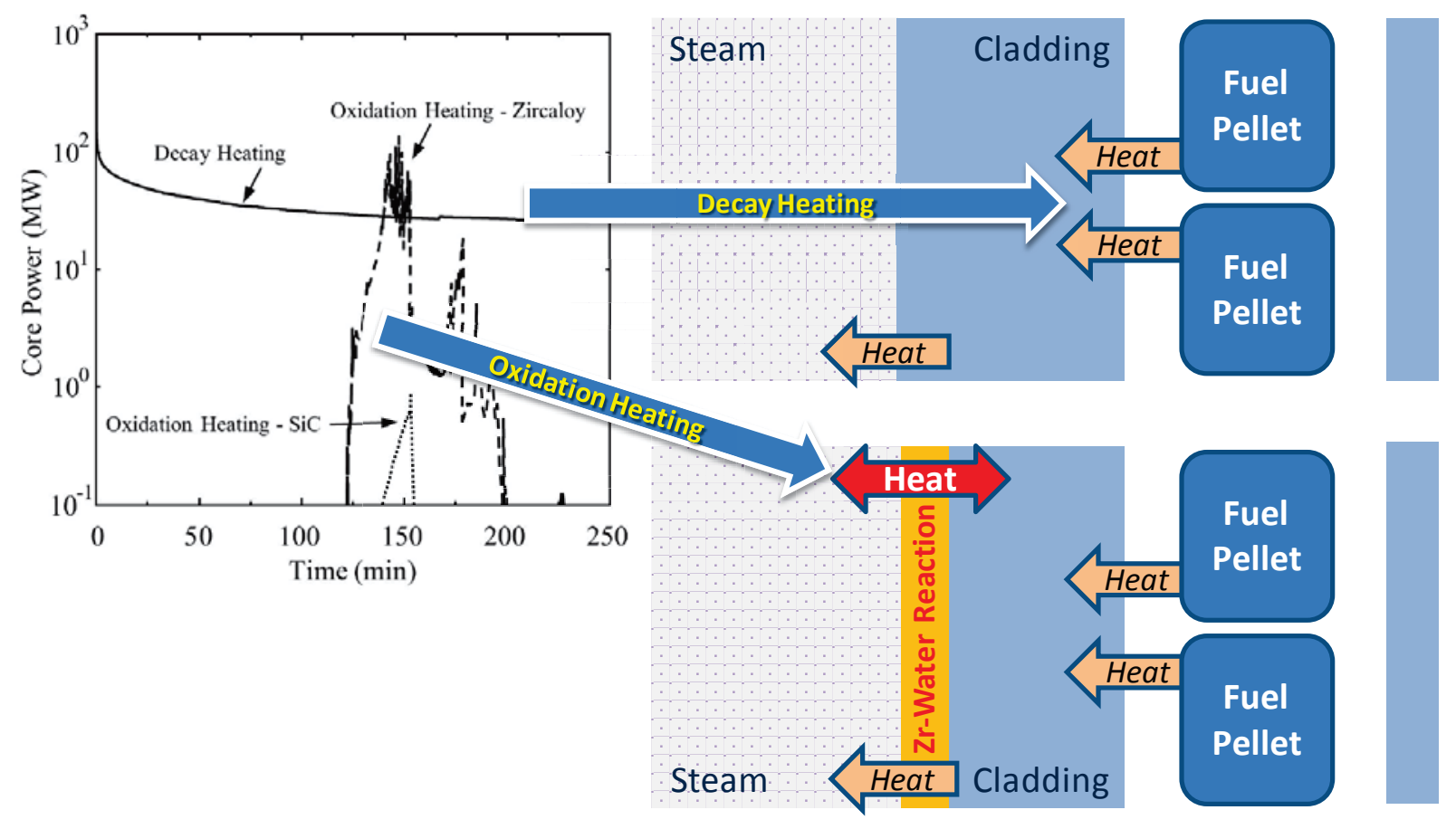

Figure 4. Heat from Fuel vs. Heat from [Fuel + Zr-Water Reaction]

Decades ago, safety investigators ${ }^{\mathrm{b}}$ opined that water level in the core would be a better indicator of the situation than the temperature calculated in a node of a T/H code. From this point of view, it is not completely natural to view "temperature" solely as a "load" on Zircaloy cladding. It is arguably more natural to focus the concept of "load" on physical things that the plant does to the fuel that it should not (e.g., apply mechanical stresses), or things that the plant does not do that it should (e.g., the plant should keep the core covered, and failure to do this challenges the fuel), and to analyze the "load" concept in such a way as to be able to map load in a given scenario onto a cumulative damage concept [11].

In fact, the current regulatory acceptance criterion already has a cumulative damage limit on oxidation $(<17 \%$ ) (a necessary but not sufficient condition for acceptable cooling system performance). We will return to this point later.

From a formal point of view, a comparison of two systems in a specific issue space should carefully consider how to condition "failure" probability appropriately. The reference [7] work did not really condition the two time histories in quite the same way: rather, reference [7] followed the TMI time-line in detail for Zircaloy, and followed it again for $\mathrm{SiC}$, and then made a seemingly straightforward comparison between $\mathrm{SiC}$ and Zircaloy. This approach was satisfactory for the point of that article, but in general, a slightly different approach would be needed to support the comparison that we really want to make. In particular, a more general approach would need to consider whether the $\mathrm{SiC}$ response to its environment would change the environment itself. If, for example, the evolution of hydrogen in the reactor coolant system changed anything about core behavior or natural circulation behavior, then there would be something wrong with a comparison derived by imposing identical reactor coolant system conditions on the two different cladding types. The high-level intuition might be essentially unchanged, but detailed interpretation of the comparison would no longer be simple.

\footnotetext{
${ }^{\mathrm{b}}$ E.g., Leonard Ward, formerly of SCIENTECH (personal communication).
} 
In order to address this issue correctly, we need to return to the concept of the issue space, and apply it in a carefully considered fashion.

Two kinds of uncertainty are associated with the degrees of freedom whose variation is being considered in a given issue space: aleatory and epistemic. A large body of literature already discusses these concepts.

Operationally, it is useful to focus on the point that the word "aleatory" refers to "dice," and, in the present context, to the point that in repeated trials of a given system operation, the behavior of the aleatory degrees of freedom will vary from one trial to the next. We simply don't know in detail what the will happen in the next stochastic trial, even after some observations of previous trials. A typical example is failure of an active component, say a coolant pump, to actuate on demand. We may be willing to bound the probability of failure, but in the real world, we won't be certain beforehand of the outcome of a particular trial.

Epistemic uncertainty refers to something that we do not know, but does not change "much" from trial to trial. For example, uncertainty in the probability of failure in the active-component example mentioned above is commonly treated as epistemic. Illustrated graphically, these two uncertainty concepts (aleatory and epistemic) as shown in Figure 5.

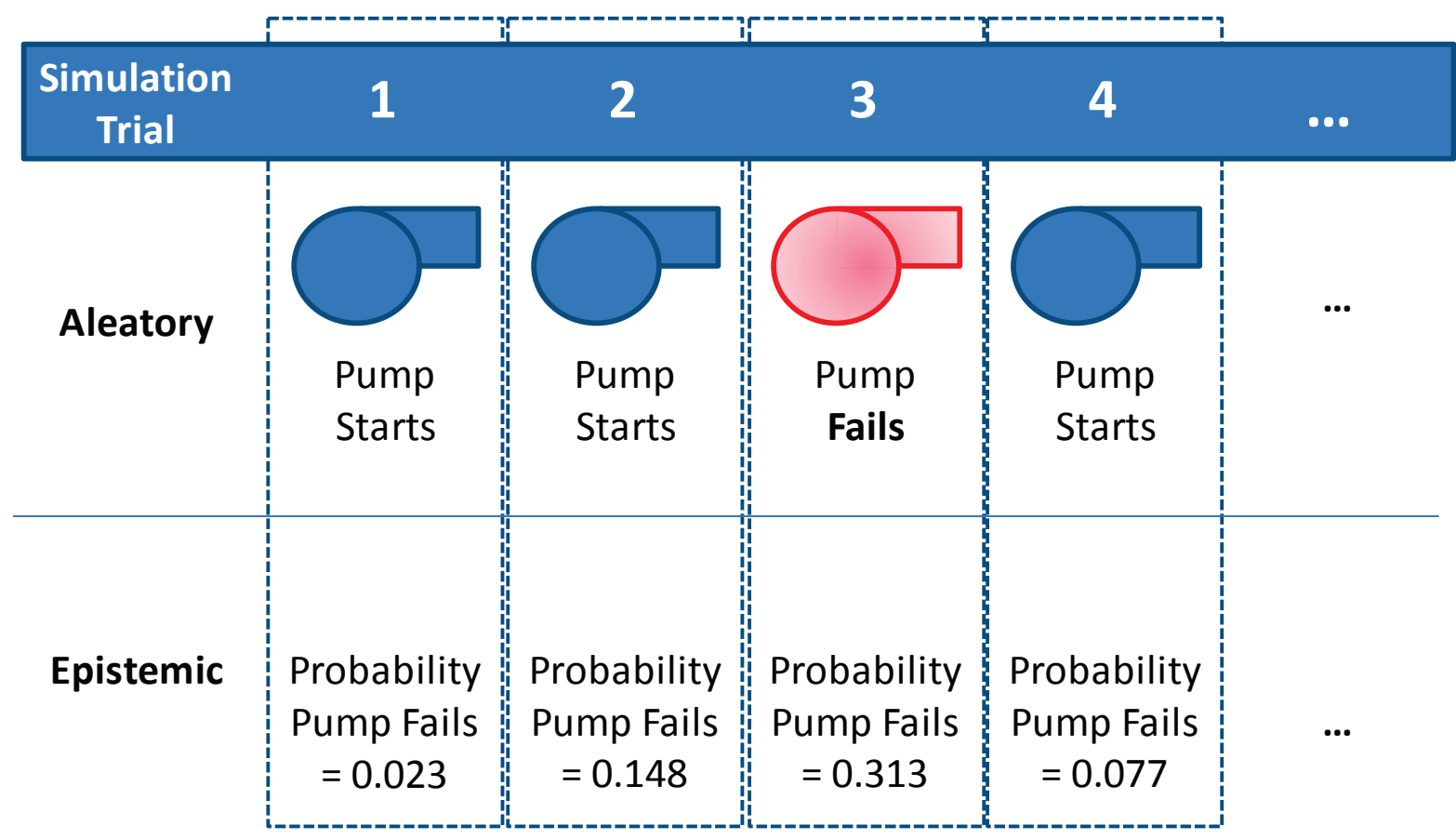

Figure 5. Illustration of aleatory and epistemic uncertainties.

If we perform enough simulation trials, we could develop a good estimate of the active component failure probability, and thereby reduce the epistemic uncertainty; but based only on evidence from a finite number of trials, we still would not know for certain whether a failure will occur on the next trial.

On what, then, do we base a comparison of cladding types, if the cladding behavior itself influences the time line of the system operation in which the cladding is embedded? And how do these uncertainty concepts play a role?

\footnotetext{
c Alea iacta est: "the die is cast." Imputed to Caesar; associated with his crossing of the Rubicon.
} 
An implementable picture of the needed capability was provided in references [11] and [12], which discussed how to combine aleatory behavior and phenomenology in a given simulation. The idea is that the reliability model of a given component type is simply an expression of the variation in how much wear and tear an individual component will take before it fails. Put another way: a population of components manufactured, installed, and operated in as uniform a way as possible, will not all fail at the same instant. Their collective failure times will follow a characteristic reliability function, but they vary individually in their behavior as a function of accumulating wear and tear. Within this picture, failure occurs in a particular time history when some parameter (which could be "wear and tear," or could be something else) accumulates up to a threshold value. ${ }^{\mathrm{d}}$ Further, this idea is generalizable to stochastic outcomes whose behavior at a time $t$ has an aleatory character but depends on the history preceding that time. For example, the timing of an operator performance of a procedural action has an aleatory character, but can arguably be modeled in terms of the time history of the cues leading up to the execution.

Having re-introduced the cumulative damage idea, we can point out that existing regulatory acceptance criteria for ECCS performance already invoke a simplified form of it: they call for zirconium oxidation $<17 \%$. Within this concept, one might in principle calculate a more complicated cumulative damage index corresponding more directly to loss of ductility, based on the experimental finding that loss of ductility relates not only to the percent of oxidation but also to the temperature, upon which latter observation the PCT limit of $2200^{\circ} \mathrm{F}$ is based.

Even without involving the cumulative-damage idea, there is no reason to suppose that actuation of pumps will, in general, take place at the same time in two timelines (as in [7]), if pump actuation depends on the physics, and the physics changes appreciably between the timelines.

If one wishes to compare conditional probabilities of failure for two cladding designs within a wellformulated issue space, one ought to compare a large set of off-normal scenario timelines across which the stochastic behavior is established consistently according to the cumulative damage concept. If a given component is destined to actuate (or fail, or trip) on a particular condition, and that condition varies because of a difference in cladding behavior, we want the component actuation (or failure, or trip) to vary. The principle is that all of the epistemic uncertainties and all aleatory variations are sampled before the time line is generated, and the time line is then determined by physics, which may vary across cladding types.

If SiC's different chemistry (of the oxidation reaction) would have changed the TMI timeline of active component operation, primary level, etc., then strictly speaking, the simulations performed in the [7] study would not actually comply with this requirement. It is re-emphasized that this does not call into question the interest in the comparison, or the essential points of the article, which are (1) MELCOR was successfully enhanced by the addition of an $\mathrm{SiC}$ model, (2) fuel rod heatup is very significantly changed as a result, because the $\mathrm{SiC}$ oxidation reaction adds much, much less heat than the $\mathrm{Zr}$ oxidation reaction.

\footnotetext{
${ }^{\mathrm{d}}$ Note, however, that this formulation even allows for healing.
} 


\section{The Issue Space}

Any given analysis of performance is predicated on many things, some tacit, some explicit. In order to be interpretable, the analysis needs to be carried out on the basis of clearly stated assumptions, including some indication of which degrees of freedom are allowed to vary in the analysis, and which are fixed. Let us call this specification the "issue space" for that particular evaluation. It includes:

- Model parameter value ranges

- Variability or uncertainty in initial conditions

- Scope of equipment failures analyzed:

$\circ$ Some in scope, some not

- Some assumed always to occur, some assumed not to occur

- Sometimes failure time is among the sampled parameter values

- Scope of modeled variations in what operators may do

- Parameters and degrees of freedom that are fixed in the analysis, and an indication of the implications of this for interpretation of the analysis results

The issue space associated with a given evaluation depends on the decision being supported, along with numerous other factors.

As formulated, this concept is meant to include classical safety analysis as a special case: for example, analysis of system performance conditional on a limiting single failure subsequent to a specific initiating event such as loss of offsite power. The issue space covers all scenarios characterized by a single failure, operating conditions chosen to be within technical specifications but otherwise limiting, limited or no credit for human action, etc. But in classical safety analysis, the point is to show that limiting performance is still acceptable, while for present purposes, the point is to show the spectrum of behavior within the issue space, and the probabilities of the various outcomes.

It would be very convenient to be able to unleash an adaptive-learning algorithm using simulation to determine the limiting cases (the limiting failure modes are in various regions of the issue space). But even that ideal case would require that the failure modes be addressed in the simulation model. As a practical matter, formulation of the issue space must carefully consider which failure modes to include, because the simulation model must be capable of addressing and capturing them.

In summary, the regulatory acceptance criteria for DB LOCA were based on a perceived need to maintain geometry immediately following the event and for some time after. This required that the cladding remain ductile, so that assemblies would not shatter as they were unloaded, which would create an unfortunate scenario, and the acceptance criteria were formulated correspondingly, based on the experimental state of knowledge at the time. The MELCOR runs from [7] use a very different failure criterion because a very different question is being answered. 


\section{CASE STUDY PROCESS \\ 4.1 General Considerations}

The first step is to conduct a preliminary assessment of the safety performance expected from each candidate technology on the basis of the current state of knowledge regarding that technology, and to do so in a way that supports intelligible comparison with the technology currently in use, as well as comparisons among candidate new technologies.

For purposes of this section:

- "Safety performance" is interpreted within two issue spaces: analysis of design-basis accidents, and analysis in severe (beyond-design-basis) accidents.

- "Risk-Informed" is defined in many places, ${ }^{\mathrm{e}}$ but operationally, for present purposes, "riskinformed characterization" means (1) consideration of all probabilistically significant scenarios occurring within a given issue space, including variability in timing, as opposed to focusing on an ostensibly limiting case, and (2) explicit consideration of uncertainties.

- "Issue space" is used as defined on Page 11.

Within the RISMC Pathway of the LWRS program, emphasis has been placed on the evaluation of safety margins in an essentially risk-informed way. Classically, "margin" is defined in terms of a distance between a designated nominal value of a particular performance parameter, and a threshold value at which some kind of failure would occur; a familiar example is margin to structural failure, assessed based on the capacity of a given structure to withstand a particular load, and an assessed load value that is unlikely to be exceeded in practice. The classical concept of "margin" has always contemplated allowance in design for variability and uncertainty, but usually without detailed characterization of the load and capacity spectra. Within RISMC, "margin" is characterized in terms of the probability of a particular functional failure, which, in simple cases, can be assessed in terms of the probability density function of applied load, and the probability density function of capacity to withstand that load.

\subsection{Formulation of the Issue Spaces for Evaluation}

For present purposes, two issue spaces will be discussed: one associated with evaluation of performance in a Large-Break LOCA, and one associated with severe-accident performance in an extended station blackout. As discussed elsewhere in this report, the full evaluation will consider other issue spaces as well, but for present purposes, the important points can be raised in connection with these two. Design-basis regulatory acceptance criteria are of particular interest in the case of LBLOCA, while performance in severe accidents (such as extended blackout) involves other issues.

As defined earlier in this report, "metrics" describe a set of technical bases by which multiple concepts can be fairly evaluated against a common baseline and against one another. In the context of safety, this means that "failure" must be defined with respect to functionality, in a way that has the same meaning across ATF concepts. Different ATF concepts may fail functionally as a result of different physical mechanisms; reaching a particular elevated temperature (such as $2200 \mathrm{~F}$ ) has significance for current technologies, but not necessarily for technologies that use different materials.

\footnotetext{
${ }^{\mathrm{e}}$ On the NRC website, the definition is given as follows: "Risk-informed decisionmaking: An approach to regulatory decisionmaking, in which insights from probabilistic risk assessment are considered with other engineering insights." In the NRC website formulation, the phrase "risk-informed" is being applied to "decision-making," and the main point is that PRA is one of several inputs to the decision. The overall approach described in this report is risk-informed in the NRC sense; within the present section, emphasis is placed on performance within the issue space as a whole, and on consideration of uncertainty and variability.
} 
For different technologies, it is necessary to start with the same objective on a key physical property (say, "ductility"), characterize it in terms of lower-level physical parameters analogous to (but distinct from) the temperature and oxidation limits mentioned above, and define appropriate failure thresholds. These steps position the analysis to quantify the probability of functional failure in terms of the probability of exceedance of the technology-specific thresholds, and moreover to yield information about the scenarios within which these failures occurred: what equipment failed, which timing peculiarities exacerbated the scenario, which uncertainties allowed for the possibility of this outcome.

\subsubsection{Large-Break LOCA}

As discussed later in this report, the specification of figures of merit to be analyzed in classical design-basis analysis was informed by consideration of the need to maintain coolable geometry, during an accident and later on, including fuel handling. Embrittlement to the point of threatening this objective was seen as unacceptable (within the design basis), and the current regulatory acceptance criteria on peak cladding temperature and oxidation were formulated accordingly for current cladding technology, based on experimental evidence available at the time. In severe-accident space, the objective is formulated quite differently, and a different failure criterion is commonly used, as discussed below.

For purposes of the technology comparison, the same high-level regulatory objectives need to be considered for all technologies, and mapped for each technology onto specific parameters whose exceedance of designated threshold values would fail the safety function.

For some purposes, it would be interesting to analyze LBLOCA as if doing an evaluation of the safety analysis report Chapter 15 success path. This essentially says "we know the limiting setting of key aleatory ${ }^{\text {f }}$ degrees of freedom (e.g., concurrent LOOP and loss of one electrical division), and we set those degrees of freedom accordingly, and then sample over the epistemic ${ }^{\mathrm{g}}$ uncertainties to draw inferences about the functional unreliability." For Zircaloy cladding, the analysis exists for some plants, though (as far as the present authors know) it is proprietary. The point would be to do it consistently (in the sense of that term discussed below) for multiple technologies, perhaps as a function of power level.

In principle, the simple formulation articulated above has a drawback that will be difficult to overcome. Adopting a fuel technology with completely different vulnerabilities from today's fuel technology would presumably be predicated, in part, on adoption of very different limiting conditions of operation. Power uprate, for example, might be an option, as might changes to other reactor protection parameter settings. It is not considered practical to carry out the implied plant optimization, although one could argue that a fair comparison would require such a step. Here, it will be assumed that the ECCS, the Reactor Protection System, and all Technical Specifications will remain unchanged. This somewhat complicates what can be said about the comparison.

\subsubsection{Extended SBO}

Many permutations of factors in the issue space can be considered in comparing technologies subjected to SBO. Section 3.2 of the Regulatory Position in Regulatory Guide 1.155 defines a comprehensive issue space, a subset of which could be considered for an illustrative case study.

- Which plant types to analyze (vendor, model, physical site, ... )

- Numerous aleatory aspects (for example, the timing of recovery of AC power)

\footnotetext{
${ }^{\mathrm{f}}$ Things that vary from one real-world trial to the next.

${ }^{\mathrm{g}}$ State-of-knowledge.
} 
- Considerations identified in Section 3.2 of Regulatory Guide 1.155 (availability of key systems, RCP seal leakage).

Fukushima-style external events were not within SBO-rule scope at the time of the promulgation of the Station Blackout rule. Today, some would argue that protracted SBO situations resulting from severe external events ought to be considered. Currently, external flood is receiving significant attention because of a perception that external flood risk has been underestimated.

\subsection{Assessment Steps}

In light of the above considerations, the RISMC methodology steps (see Figure 6) are used to evaluate various alternatives. Specifically, the following steps are to be carried out for each designated issue space, for each candidate technology.

1. Formulate an issue space that spans both regulatory and investment interests. Formulate definitions of functional failure in terms of figures of merit relating to the likelihood of the following outcomes, and characterization of the conditions under which failure occurs. Possible examples:

- Significant Loss of ductility of fuel rods (the basis for current regulatory acceptance criteria: deemed to have occurred if oxidation $>17 \%$ OR PCT $>2200 \mathrm{~F}$ )

- Release of radioactive material...

○ From the fuel

- Gap release

- Worse than gap release

- From the vessel

- From the containment

- Significant Loss of geometry in-core during the accident (occurs at VERY high temperature: in [7], 2500K for the Zircaloy case)

- Any alteration of the core state that would make it difficult to defuel or refuel the plant (For Zircaloy cladding, occurs at exceedance of regulatory acceptance criteria; for $\mathrm{SiC}$ alternatives, it remains to be specified, and mechanical loads in some accidents might need to be considered)

- Flammability / Detonability of evolved noncondensables

2. Conduct a tailored failure modes and effects analysis (FMEA) to establish which environmentally-induced failure modes need to be simulated in order to address the figures of merit identified above. In particular, determine which failure modes occur first as temperature is raised, what effects these modes have, and what capability the code needs to have in order to validly model them. For example, a current "failure" criterion in MELCOR for Zircaloy-clad fuel is associated with melting of a $\mathrm{ZrO}_{2}-\mathrm{UO}_{2}$ eutectic:

- In the MELCOR code, this failure criterion is purely a temperature set point based on experimental data and modeling experience, which coincides with the melting temperature of a UO2-ZrO2 eutectic $(\sim 2500 \mathrm{~K})$. At this time, MELCOR transfers the rod's fuel and cladding into a debris field in the coolant channel, where channel blockage and debris heating accelerates core damage in lower regions of the core. [7] 


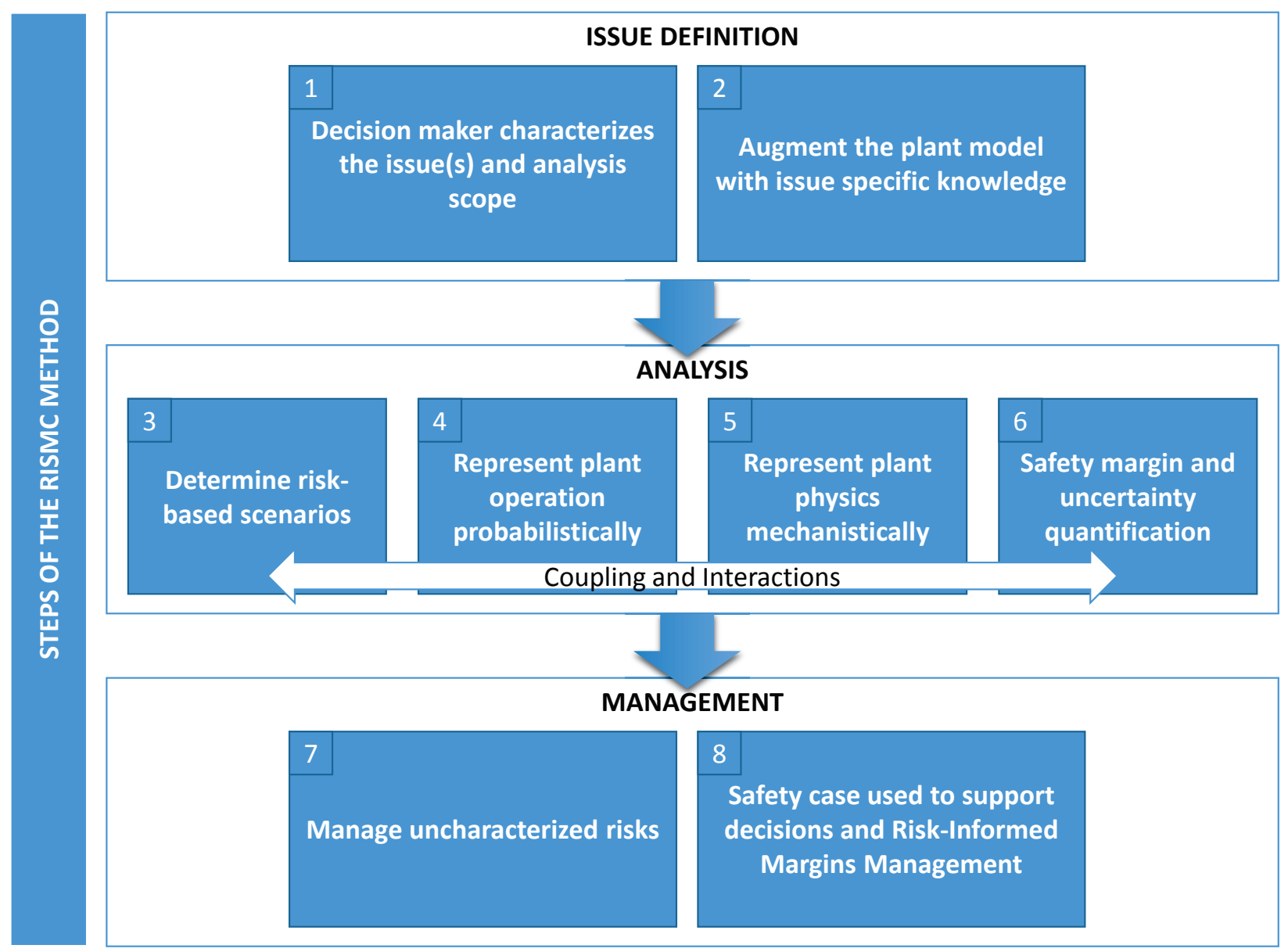

Figure 6. Steps of the RISMC safety margin methodology.

In a technology that made no use of $\mathrm{Zr}$, this failure mode would not play a role. Note, however, that some cladding technologies that are under discussion and that use SiC also still use Zircaloy.

3. Choose families of scenarios to analyze: families of scenarios on which it makes sense to condition the comparison. Within the following categories of scenarios, choose specific initiators and specific classes of aleatory variations to allow in the sampling.

- Families of Scenarios:

- DBA analysis.

- Non-DBA accident sequence analysis.

- Sequences that threaten the public

- Sequences that threaten workers

- Sequences that threaten the plant.

- Event Sequences that take the plant offline.

- Normal operation (evolutions affecting useful life of the fuel)

- Classes of Aleatory Variations:

- Point in Core Life Cycle 
○ Component Failures / Deviations (e.g., tech spec violations) over which to sample

O Operator actions

- Variation in fuel condition before accident: nicks in SiC outer cladding, for example; varying burnups;

- Conduct a PIRT (Phenomena Identification and Ranking Table) exercise in order to be sure that the phenomena that need to be modeled in the simulation code, for current purposes, are, in fact, modeled. This step is important in light of the introduction of novel components and novel materials into the subject technology, and the novel failure modes that need to be addressed. If new phenomena need to be added, add them.

4. Formulate models for the aleatory variables that couple to scenario phenomenology.

- For some variables, these models do not need to couple to phenomenology.

- For variables that need to couple to phenomenology, the models may beneficially use the cumulative damage idea, or an analog based on accumulated time in state (for example, an operator action may, for a time, increase in likelihood if the cue persists for a while).

- Identify key epistemic uncertainties and develop necessary uncertainty distributions.

5. Couple the aleatory behavior to applicable mechanistic models, for example through use of the MELCOR severe accident simulation software.

6. Simulate time histories supporting quantification of the figures of merit selected under Step 2 in order to determine margins, making sure that aleatory variables are sampled according to the cumulative damage principle, and that each variable setting is sampled consistently for each technology analyzed, so that the figures of merit can be validly compared across technologies from the results for each technology analyzed

7. Perform sensitivity analysis to determine limitations and drivers of the analysis. Expert judgment will be required in order to determine where unknown or un-modeled issues may be important to decision making.

8. Quantify results such as the probability of failure, conditional on each issue space, consistently across candidate technologies. Determine principal contributors to functional failure probability. 


\section{CONCLUSIONS}

Analyzing the behavior of novel fuel types, especially comparing safety-relevant performance characteristics, needs to consider the following.

- The simple load-capacity idea that has previously been used to explain RISMC is oversimplified for purposes of addressing fuel performance. The concept that margin needs to be quantified probabilistically remains applicable, but trying to compute separate load and capacity curves for fuel cladding as if they are independent is inapplicable: the character of the challenges to fuel integrity is, to some extent, determined by the fuel itself.

- In order to validly compare the performance of different cladding types based on simulation, it is necessary to prepare the simulation inputs for each cladding type in a consistent way. This is not necessarily accomplished by making the external specification of accident scenario timing the same in the various runs; different behavior by different cladding types may change (e.g., delay, accelerate, halt) the actual timing of key phenomena-based events. Instead, it is important to:

○ Carefully formulate the issue space on which the comparison is to be based, considering applicable uncertainties,

○ Formulate cumulative-damage models for each stochastic event, and

- Perform simulation trials for each cladding type in which the sampling of underlying uncertainty is done consistently.

These steps do not guarantee that the sampling will be sufficient (that enough of the right runs get done to cover the issue space adequately), but they help assure consistency.

- It is the plant-level outcome that matters in deciding the value of supposed improvements in cladding. Deciding whether a given cladding is "better" needs to be informed by a probabilistic insight. If a given cladding buys (on average, in scenarios spanning the relevant issue space) 10 hours of extra response, that is probably significant; if its increased robustness buys only a short time within the issue space (perhaps because of its own properties), that short time may not be significant.

- Failures of other RCS components may moot the performance of the cladding itself. If cladding is changed so that a different failure mode becomes limiting, we need to know that other failure mode, and may need to include it in the simulation model, if the issue space comprises scenarios that go to that outcome. The comparison process must therefore include a search for such modes and a PIRT to make sure that the considerations relevant to the comparison are all reflected.

The detailed analysis steps presented in Section 4 have been formulated in light of the above considerations. 


\section{REFERENCES}

[1] Light Water Reactor Sustainability Program Integrated Program Plan, Revision 1, INL-EXT-1123452, April 2013.

[2] TMI-2: An Event in Accident Management for Light-Water-Moderated Reactors, by Robert E. Henry (American Nuclear Society, 2011).

[3] R. Gauntt et al., "Fukushima Daiichi Accident Study (Status as of April 2012)," Sandia National Laboratory, SAND-2012-6173, 2012.

[4] The History of LOCA Embrittlement Criteria, G. Hache, Institut de Protection et de Sureté Nucléaire Cadarache, France, H. M. Chung, Argonne National Laboratory, Argonne, Illinois, USA, appearing in NUREG/CP-0172, May 2001.

[5] Proposed Rulemaking - 10 CFR 50.46c: Emergency Core Cooling System Performance During LossOf-Coolant Accidents (RIN 3150-AH42), R. W. Borchardt, SECY-12-0034 (NRC, March 1, 2012).

[6] "The Commission has developed guidance and goals for resolving those safety issues related to reactor accidents more severe than the design-basis accidents (DBAs). These "severe accidents" are those in which substantial damage is done to the reactor core, regardless of whether serious offsite consequences occur." -- Final Safety Evaluation Report Related to Certification of the AP1000 Standard Design (NUREG-1793, Initial Report), Chapter 19.

[7] B. J. Merrill, and S. M. Bragg-Sitton, "SiC Modifications to MELCOR for Severe Accident Analysis Applications," 2013 LWR Fuel Performance Meeting/TopFuel, American Nuclear Society, Charlotte, North Carolina, USA, September 15-19 (2013).

[8]Advanced Fuels Campaign: Light Water Reactor Accident Tolerant Fuel Performance Metrics, INL/EXT-13-29957, FCRD-FUEL-2013-000264, S. Bragg-Sitton et al., August 2013.

[9] A Next Generation of System Simulation Codes to Support the Safety Case of the LWR Life Extension: Development, Selection, Implementation, and Testing of Architectural Features and Solution Techniques, Robert Nourgaliev, Nam Dinh, and Robert Youngblood (M2LIN10RIS1510405, September 2010).

[10] Summary of Risk-Informed Safety Margin Characterization (RISMC) Working Group / Input to Near-Term RISMC Activities Based on RISMC Working Group Meeting, January 19-20, 2010, Denver, CO, Compiled by Bob Youngblood (M3LIN10RIS1510205).

[11] Heartbeat Model for Component Failure Time in Simulation of Plant Behavior, R. W. Youngblood, R. R. Nourgaliev, D. L. Kelly, C. L. Smith, and T-N. Dinh, ANS PSA 2011 International Topical Meeting on Probabilistic Safety Assessment and Analysis, Wilmington, NC, March 13-17, 2011, on CD-ROM, American Nuclear Society, LaGrange Park, IL (2011).

[12] Risk Informed Safety Margin Characterization (RISMC) Advanced Test Reactor Demonstration Case Study, C. Smith, D. Schwieder, C. Phelan, A. Bui, and P. Bayless, INL/EXT-12-27015 (2012). 